\title{
Differential interactions of Verticillium longisporum and $V$. dahliae with Brassica napus detected with molecular and histological techniques
}

\author{
C. Eynck • B. Koopmann · G. Grunewaldt-Stoecker • \\ P. Karlovsky $\cdot$ A. von Tiedemann
}

Received: 3 August 2006/Accepted: 19 April 2007/Published online: 9 May 2007

(C) KNPV 2007

\begin{abstract}
The differential interactions of $V$. longispo$\operatorname{rum}(\mathrm{VL})$ and $V$. dahliae (VD) on the root surface and in the root and shoot vascular system of Brassica napus were studied by confocal laser scanning microscopy (CLSM), using GFP tagging and conventional fluorescence dyes, acid fuchsin and acridin orange. VL and VD transformants expressing sGFP were generated by Agrobacterium-mediated transformation. GFP signals were less homogenous and GFP tagging performed less satisfactory than the conventional fluorescence staining when both were studied with CLSM. Interactions of both pathogens were largely restricted to the root hair zone. At $24 \mathrm{~h}$ post-inoculation (hpi), hyphae of VL and VD were found intensely interwoven with the root hairs. Hyphae of VL followed the root hairs towards the root surface. At 36 hpi, VL hyphae started to cover the roots
\end{abstract}

C. Eynck · B. Koopmann · A. von Tiedemann $(\bowtie)$ Plant Pathology and Plant Protection Division, Department of Crop Sciences, Faculty of Agriculture, Georg-August University Göttingen, Grisebachstraße 6, 37077 Goettingen, Germany

e-mail: atiedem@gwdg.de

P. Karlovsky

Molecular Phytopathology and Mycotoxin Research Division, Department of Crop Sciences, Faculty of Agriculture, Georg-August University Göttingen, Grisebachstraße 6, 37077 Goettingen, Germany

G. Grunewaldt-Stoecker Institute for Plant Diseases and Plant Protection, University of Hannover, Herrenhäuser Strasse 2, 30419 Hannover, Germany with a hyphal net strictly following the grooves of the junctions of the epidermal cells. VL started to penetrate the root epidermal cells without any conspicuous infection structures. Subsequently, hyphae grew intracellularly and intercellularly through the root cortex towards the central cylinder, without inducing any visible plant responses. Colonisation of the xylem vessels in the shoot with VL was restricted to individual vessels entirely filled with mycelium and conidia, while adjacent vessels remained completely unaffected. This may explain why no wilt symptoms occur in B. napus infected with VL. Elevated amounts of fungal DNA were detectable in the hypocotyls 14 days post-inoculation (dpi) and in the leaves 35 dpi. Root penetration was also observed for VD, however, with no directed root surface growth and mainly an intercellular invasion of the root tissue. In contrast to VL, VD started ample formation of conidia on the roots, and was unable to spread systemically into the shoots. VD did not form microsclerotia in the root tissue as widely observed for VL. This study confirms that VD is non-pathogenic on B. napus and demonstrates that non-host resistance against this fungus materializes in restriction of systemic spread rather than inhibition of penetration.

Keywords Oilseed rape · GFP · Confocal laser microscopy $\cdot$ Agrobacterium-mediated transformation · Non-host resistance $\cdot$ Vascular diseases 


\section{Introduction}

Verticillium wilt on oilseed rape (Brassica napus spp. oleifera) is caused by the host-adapted, near-diploid fungus Verticillium longisporum (Karapapa et al. 1997b; Zeise and von Tiedemann 2001, 2002a, b). The growing area of rapeseed cultivation and the relatively intense crop rotation has rendered this disease an increasing threat to oilseed rape (OSR) production particularly in Europe (Krüger 1989; Zielenski and Sadowski 1995). In Sweden, Verticillium wilt has been known as the cause of economic losses of OSR since the 1960s (Svenson and Lerenius 1987) and has become a significant problem since the 1970s (Dixelius et al. 2005). In the main cropping areas for winter OSR in Germany, the occurrence of $V$. longisporum has increased rapidly since the mid 1980s (Daebeler et al. 1988; Zeise and Seidel 1990; Günzelmann and Paul 1990). For both winter and spring type OSR, breeding for resistance has been severely hampered by the absence of sufficient resistance in commercially available breeding material; however, recently, some promising genotypes of cabbage (B. oleracea) with enhanced resistance were identified (Happstadius et al. 2003; Dixelius et al. 2005).

A closely related species to $V$. longisporum is $V$. dahliae. This ubiquitous soilborne fungus causes wilt diseases on many economically important crops, including cotton, cucurbits, alfalfa, sunflower, eggplant, mint, strawberry, tomato and potato (Domsch et al. 1980; Schnathorst 1981; Pegg 1984; Subbarao et al. 1995; Bhat and Subbarao 1999). A differentiation of long-spored Verticillium isolates collected from horseradish, classified as $V$. dahliae var. longisporum, was first made in the early 1960s (Stark 1961), until the detailed description of distinct morphological, physiological and molecular traits led to the proposition of treating $V$. longisporum as a distinct species (Karapapa et al. 1997b). Nonetheless, there is still controversy concerning the taxonomy of $V$. longisporum as a separate host-specific species of Verticillium (Fahleson et al. 2003). Thus it has been reported that Brassica crops can occasionally host short-spored Verticillium isolates (Collins et al. 2003) and that $V$. longisporum is able to infect plant species outside the Brassicaceae family (Fahleson et al. 2003; Johannson et al. 2006). Additional confusion has been caused by some misidentification of the two species. In several studies, $V$. dahliae has been regarded as the causal agent of Verticillium wilt in Brassica crops (Xiao and Subbarao 2000; Söchting and Verreet 2004) or on horseradish (Babadoost et al. 2004), without considering that long-spored isolates may have been involved.

The host range, epidemiology and infection process on various hosts of $V$. dahliae have been intensely investigated in previous works (Schnathorst 1981; Beckmann 1987; Gold et al. 1996; Rowe and Powelson 2002). After germination of microsclerotia, which is inducible by the root exudates of host plants (Mol and Scholte 1995), the fungal hyphae reach the root surface, penetrate the epidermal cells, transverse the root cortex and enter the immature xylem elements (Beckman 1987). Most of the time of its life cycle $V$. dahliae is constricted to the vascular system, which is a nutrient-limited environment containing low amounts of sugars, inorganic salts, and amino acids, to which the fungus is well adapted (Wood 1961; Dimond 1970; Dixon and Pegg 1972; Green 1981; Pegg 1981, 1985; Van Alfen 1989). In this liquid environment $V$. dahliae exhibits both hyphal and a 'yeast-like' growth, producing conidia budding directly from hyphae, or formed on short phialides (Buckley et al. 1969). With the transpiration stream the released conidia are carried upwards in the vascular elements where they are eventually trapped in bordered pits or at vessel end walls. Colonization proceeds by formation of germ tubes, which penetrate into the upstream vessel elements where new conidia are produced (Beckman 1987; Gold et al. 1996). In the later stages of the disease cycle, as the foliage begins to senesce, the pathogen enters a limited saprophytic growth phase in which microsclerotia are formed in the dying stem parenchyma, thus having a critical role as the primary source of disease in the field (Schnathorst 1981; Neumann and Dobinson 2003).

Currently, little is known about the infection patterns of both $V$. longisporum and $V$. dahliae on roots of $B$. napus. In order to visualize their colonization of the oilseed rape rhizosphere by confocal laser scanning microscopy (CLSM), we used the green fluorescent protein (GFP) from the jellyfish Aequorea victoria (Chalfie and Kain 1998; Tsien 1998) to label both $V$. longisporum and $V$. dahliae. Since the first report on the use of GFP as a vital marker in plant-pathogen-interaction studies 
(Spellig et al. 1996), the GFP transformation has become a common tool in the analysis of various fungal/fungus-like plant pathogens (Lorang et al. 2001). A particular advantage of the method is that plant infection and colonization of GFP-expressing fungi can be followed by fluorescence microscopy in intact plant tissues or tissue sections without requiring cofactors or substrates (Horowitz et al. 2002; Shan and Godwin 2004; Bolwerk et al. 2005).

In the present study the GFP-labelling was compared with a technique combining conventional fluorescence staining with confocal microscopy. We describe (i) the Agrobacterium tumefaciens mediated transformation of both $V$. longisporum and $V$. dahliae resulting in stable expression of GFP, (ii) compare the suitability of the GFP reporter gene technique with classical fluorescence staining and (iii) describe new aspects in the early and advanced stages of $V$. longisporum and $V$. dahliae on the roots and in the vascular system of oilseed rape. The microscopical results are further supported by the documentation of disease development by real-time PCR analysis of fungal DNA.

\section{Materials and methods}

Plant material

The susceptible winter oilseed rape variety 'Falcon', supplied by Norddeutsche Pflanzenzucht Hans-Georg Lembke KG (NPZ), was used in this study. Seeds were double surface-sterilized by sequential immersion in $70 \%$ ethanol for $2 \mathrm{~min}$ and $1 \%$ sodium hypochlorite containing $0.1 \%$ Tween-20 for $15 \mathrm{~min}$ under constant shaking (Zou et al. 2004). Subsequently, seeds were washed two times with autoclaved tap water.

Fungal isolates

Verticillium longisporum isolate VL 43 from Brassica napus and V. dahliae isolate VD 73 (vegetative compatibility group 2B) from Linum usitatissimum were used throughout this work. Both isolates originated from hosts grown in the north of Germany (Zeise and von Tiedemann 2001, 2002a, b). Longterm storage with conidial suspensions in a concentration of $1-3 \times 10^{6}$ conidia $\mathrm{ml}^{-1}$ in Czapek Dox medium supplemented with $25 \%$ glycerol at $-80^{\circ} \mathrm{C}$ was used. For propagation, droplets of these suspensions were plated onto potato dextrose agar (PDA) and incubated for 14 days at $23^{\circ} \mathrm{C}$ in the dark. Spores were obtained by gently flooding the dishes with $0.9 \% \mathrm{NaCl}$ solution (modified according to Melouk 1992). Inoculum for root dip inoculation was produced by adding $500 \mu \mathrm{l}$ of the spore stock solution to $250 \mathrm{ml}$ potato dextrose broth (PDB). The cultures were subsequently incubated for 7 days at $23^{\circ} \mathrm{C}$ on the rotary shaker. The resulting suspension was filtered through sterile gauze. Spore concentration was determined with a haemocytometer and diluted to $1 \times 10^{6}$ spores $\mathrm{ml}^{-1}$.

\section{Bacterial vector strain}

Escherichia coli strain DH5 $\alpha$ (Hanahan 1983) was used during construction and maintenance of plasmids. Agrobacterium tumefaciens strain AGL-1 (Lazo et al. 1991) was kindly provided by Dr. Susanne Frick, Leibniz Institute of Plant Biochemistry, Halle/Saale. This strain carries the hypervirulent $\mathrm{Ti}$ helper plasmid pTiBo542 $\Delta \mathrm{T}$, which lacks one border sequence and thus an intact T-DNA region (Hood et al. 1986; Komari et al. 1986; Lazo et al. 1991). For the transformation of plants or fungi, this strain has to carry a binary vector in which the TDNA is defined by both left and right border sequences (Bevan 1984). Short-term storage of the Agrobacterium cells was performed on solid LB (Luria Bertani) medium (Maniatis et al. 1982), supplemented with $25 \mu \mathrm{g} \mathrm{ml}{ }^{-1}$ rifampicin and $50 \mu \mathrm{g} \mathrm{ml}^{-1}$ carbenicillin at $4^{\circ} \mathrm{C}$. Cells were stored long term as electrocompetent cultures in the freezer at $-80^{\circ} \mathrm{C}$.

\section{Binary vector construction}

The binary vector used in this study was constructed on the backbone of pPK2 (Covert et al. 2001). A fragment of about $2.9 \mathrm{~kb}$ of gGFP (Maor et al. 1998), containing the sgfp gene driven by the Aspergillus nidulans promoter and terminated by the A. nidulans trpC terminator (Punt et al. 1987), was isolated by digestion with $\mathrm{XbaI}$ and EcoRI. sGFP is a variant of GFP carrying S65T mutation, which was constructed with the goal to improve optical properties of GFP expressed in plants and proved superior to wildtype 
GFP when expressed in fungal mycelium (Maor et al. 1998).

In two different reactions the plasmid pBluescript$\mathrm{SK}^{-}$(Acc. No. X52330, Short et al. 1988) was digested on the one hand with the restriction enzymes AflIII and XbaI and on the other hand with AflIII and EcoRI, leading to fragments of $450 \mathrm{bp}$ and $2.5 \mathrm{~kb}$ size, respectively. These fragments were ligated with the XbaI/EcoRI fragment from gGFP in a triparental ligation, resulting in the plasmid pBS::gpd::sgfp. Subsequently, the sGFP expression cassette was removed from pBS::gpd::sgfp again by digesting with XbaI and HindIII, which is located downstream to the EcoRI site. The resulting fragment was inserted into the corresponding XbaI/HindIII sites of pPK2. The final construct, pGV04 (Fig. 1), was introduced into A. tumefaciens by electroporation (Wen-jun and Forde 1989) at $2.5 \mathrm{kV}, 400 \mathrm{ohms}$ and $25 \mu \mathrm{F}$ using a cuvette with a $1 \mathrm{~mm}$ gap between the electrodes.

Agrobacterium-mediated transformation of V. longisporum and V. dahliae

The A. tumefaciens strain AGL1, containing the binary vector pGV04, was grown at $28^{\circ} \mathrm{C}$ for $48 \mathrm{~h}$

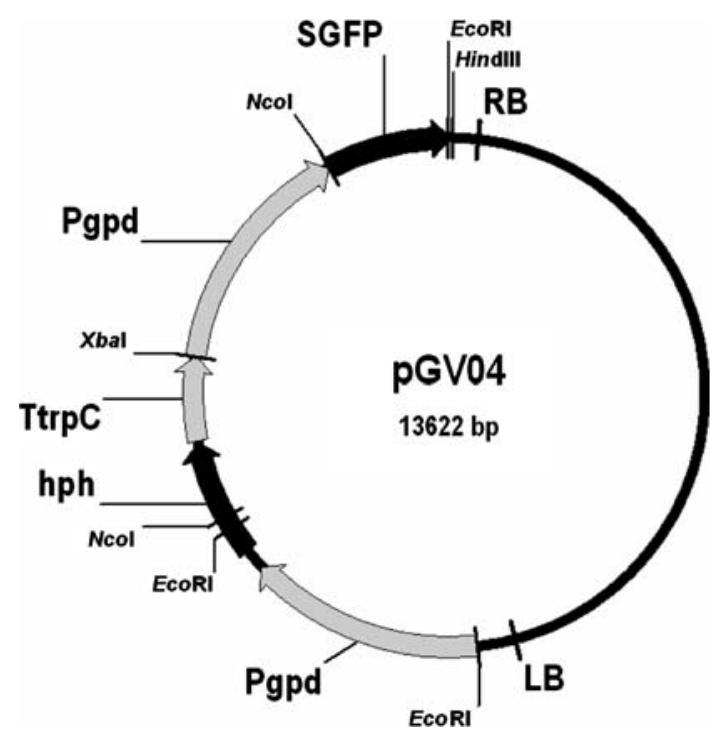

Fig. 1 Restriction enzyme map of pGV04, an Agrobacterium binary vector constructed on the backbone of pPK2 (Covert et al. 2001). The T-DNA is running clockwise from the left border (LB) to the right border (RB). Pgpd: Aspergillus nidulans glyceraldehydes 3-phosphate promoter; hph: hygromycin B resistance as a selection marker; TtrpC: A. nidulans transcriptional terminator in LB medium supplemented with rifampicin (25 $\mu \mathrm{g} \mathrm{ml}^{-1}$ ), carbenicillin $\left(25 \mu \mathrm{g} \mathrm{ml} \mathrm{m}^{-1}\right.$ ) and kanamycin $\left(50 \mu \mathrm{g} \mathrm{ml}^{-1}\right)$. After reaching an optical density of $\mathrm{OD}_{660}=0.6-0.9$ bacterial cells were harvested and washed with induction medium (IM, Bundock et al. 1995) supplemented with $200 \mu \mathrm{M}$ acetosyringone (AS). Subsequently, the bacterial suspension was diluted with induction medium to $\mathrm{OD}_{660}=0.15$. The cells were grown for an additional period of 6-12 $\mathrm{h}$ before being mixed with an equal volume of a spore suspension of either $V$. longisporum isolate VL 43 or $V$. dahliae isolate VD $73\left(1-3 \times 10^{6}\right.$ spores $\left.\mathrm{ml}^{-1}\right)$. From this mixture aliquots of $200 \mu \mathrm{l}$ were plated on a cellophane membrane placed on solid cocultivation medium (same composition as IM except that it contains $5 \mathrm{mM}$ glucose instead of $10 \mathrm{mM}$ glucose) supplemented with $200 \mu \mathrm{M}$ acetosyringone. After cocultivation at $23^{\circ} \mathrm{C}$ for $60 \mathrm{~h}$ the growing fungal mycelium and the Agrobacteria were suspended in $0.9 \% \mathrm{NaCl}$ solution supplemented with $200 \mu \mathrm{M}$ cefotaxim (for separation from A. tumefaciens) and plated on Czapek Dox medium containing hygromycin $\mathrm{B}\left(50 \mu \mathrm{g} \mathrm{ml}^{-1}\right)$ as a selection agent for the transformed fungi and again cefotaxim $(200 \mu \mathrm{M})$. The plates were incubated at $23^{\circ} \mathrm{C}$ and after 8 10 days discrete colonies developed. Each colony was checked under the fluorescence microscope and those showing the typical GFP fluorescence were subcultured for further studies. To determine their mitotic stability, all transformants were successively cultured in PDB for at least seven generations without supplementation of hygromycin B and checked under the fluorescence microscope. Throughout this subcultivation, the transformants did not show any alterations in growth or colony morphology compared to the wild-type.

In vitro root inoculation assay

Sterilized seeds of B. napus cv. 'Falcon' were sown on a cellophane membrane placed on water agar in Petri dishes, preventing the roots from growing into the medium and therefore allowing for an undisturbed microscopic analysis of the interaction between plant roots and fungus. The Petri dishes were sealed with Parafilm and subjected to a light regime of $14 / 10 \mathrm{~h}$ (light/dark) and a temperature of $23 / 20^{\circ} \mathrm{C}$ (day/night) in a climate cabinet. This system kept the intact 
plants free from contaminations by other microorganisms. After the plants had developed a welldefined root system, droplets of a spore suspension of either the transformed $V$. longisporum or the transformed $V$. dahliae strain were placed on the cellophane membrane close to the roots.

\section{Gnotobiotic sand inoculation systems}

Sterilized seeds of B. napus cv. 'Falcon' were sown in pots $(7 \times 7 \mathrm{~cm})$ containing double-autoclaved silica sand resulting in two plants per pot. This system was used in order to provide conditions for roots approximating to the unsterile situation in natural soils, but nevertheless enabling the harvest of complete clean roots without any adhering soil or organic particles. The pots were watered daily and fed two times a week with a full nutrient solution ('Flory Basisdünger', EUFLOR) throughout the experiments. Plants were kept in a controlled environment chamber at $23 / 20^{\circ} \mathrm{C}$ (day/night) and 14-h day length (Philips TL5 HO lamps).

Inoculations were either made by direct application of spore suspensions to the sand or by rootdipping. Direct inoculation was conducted one week after germination. The plantlets were inoculated by pouring $8 \mathrm{ml}$ of a spore suspension of transformed strains of $V$. longisporum or $V$. dahliae per plant on the sand surface. After inoculation, all plants were gently watered in order to wash the inoculum into the soil and to evenly spread the spores in the rhizosphere of the plants.

Root-dipping inoculation was used in the experiments for real-time PCR analysis and the documentation of symptom development in the B. napus/ $V$. longisporum and B. napus/V. dahliae interaction. After growing for 10 days, seedlings were carefully removed from the sand and the roots washed gently under tap water. Inoculation was performed by dipping the intact roots in a spore suspension of either $V$. longisporum isolate VL 43 or $V$. dahliae isolate VD 73 for $30 \mathrm{~min}$. Control plants were dipped in sterilized tap water for the same time. Subsequently, 60 plantlets of each variant (non-inoculated control, VL, VD) were transferred into pots with a sand:soil (1:1) mixture and grown in a climate chamber under standardised environmental conditions (see above).
Assessment of disease development

Plants were scored weekly for disease symptoms using an assessment key with nine classes (Table 1; following Zeise 1992, modified). Scoring was conducted weekly over five weeks. AUDPC values (area under the disease progress curve) were calculated from the disease severity values according to the following formula (Campbell and Madden 1990):

$\mathrm{AUDPC}=\sum\left(y_{i}+y_{i+1} / 2\right) *\left(t_{i+1}-t_{i}\right)$

where $y_{i}$ is the disease severity value for observation number $i, t_{i}$ is the corresponding number of days postinoculation, and $n$ the number of observations. Statistical analyses were conducted with the computer software StatGraphics. Differences among means were tested using Fisher's least significant difference (LSD).

Staining and microscopy of inoculated plant tissue

All microscopic investigations were conducted with GFP tagged strains. Examinations of the in vitro infection were started $11 \mathrm{~h}$ post-inoculation (hpi) and continued at $12 \mathrm{~h}$ intervals for the first 4 days using different plants for each time point. Additional observations were made after 3 weeks in order to examine the development of microsclerotia in the root tissue.

Examinations of plants grown in the sand system were started $24 \mathrm{hpi}$ and continued at $24 \mathrm{~h}$ intervals for 7 days and at $48 \mathrm{~h}$ intervals in the following week.

Table 1 Assessment key for scoring disease symptoms induced by Verticillum sp. on young B. napus plants inoculated in the greenhouse (following Zeise 1992, modified)

\begin{tabular}{ll}
\hline Score & Symptom description \\
\hline 1 & $\begin{array}{l}\text { no symptoms } \\
\text { slight symptoms on oldest leaf } \\
\text { (yellowing, black veins) } \\
\text { slight symptoms on next younger leaves }\end{array}$ \\
3 & about $50 \%$ of leaves show symptoms \\
4 & $>50 \%$ of leaves show symptoms \\
5 & up to $50 \%$ of leaves dead \\
6 & $>50 \%$ of leaves dead \\
7 & only apical meristem still alive \\
8 & plant dead \\
9 & \\
\hline
\end{tabular}


Furthermore, plants were investigated after 3, 4, and 5 weeks for the extent of colonization of the xylem vessels. For interaction studies with the sGFP tagged strains, whole roots where placed directly on glass slides in drops of water, covered with a cover glass, and examined. For the classical histological studies, whole roots or free-hand made sections of roots and stems were stained either with $0.05 \%$ acid fuchsin (C.I. 42685, Merck; $1 \mathrm{~g} 100 \mathrm{ml}^{-1}$ A. dest.) dissolved $1: 10$ in lactophenol or in a $1 \%$ acridine orange (C.I. 46005, Merck; 0,1 g $100 \mathrm{ml}^{-1}$ A. dest.) solution in water. After rinsing the samples either with lactophenol or water they were mounted on glass slides in drops of lactophenol or water, respectively, closed with a cover slip and immediately examined. Observations were carried out in at least four independent experiments.

Microscopic analyses were performed with a Leica TCS SP2 Confocal Laser Scanning Microscope (CLSM; Leica, Mannheim, Germany). Digital images of GFP tagged strains were acquired by scanning with $488 \mathrm{~nm}$ excitation and 520-540 nm emission filters. Settings for acid fuchsin fluorescence were $543 \mathrm{~nm}$ for excitation and 560-620 nm for emission. Digital images of acridine orange-stained specimens were acquired by two-channel-analysis with subsequent drafting of an overlay (488 $\mathrm{nm}$ for excitation/500$530 \mathrm{~nm}$ for emission and $543 \mathrm{~nm}$ for excitation/560$650 \mathrm{~nm}$ for emission). Stacks of optical sections were processed to maximum projections.

DNA extraction and real-time PCR analysis

Ten plants from each treatment were harvested for real-time PCR analysis at weekly intervals from $7 \mathrm{dpi}$ (days post-inoculation) until 35 dpi. Hypocotyls and leaves were separated resulting in twenty tissue samples and PCR analyses for each treatment. Roots were not included in the analysis as a proper discrimination between fungal biomass in the roots from fungus merely attached to the root surface through inoculation was not possible.

First, the plant tissue was ground in liquid nitrogen using a mortar and a pestle resulting in a fine powder. DNA extraction was conducted using the DNeasy Plant Mini Kit from Qiagen (Hilden, Germany). Fungal biomass was quantified by determination of fungal DNA in infected plant extracts with real-time PCR. Primers OLG 70 (CAGCGAAACGCGATATGTAG) and OLG 71 (GGCTTGTAGGGGGTTTAGA) (P. Karlovsky, unpublished) served to multiply a fragment specific for both $V$. longisporum and $V$. dahliae. For amplification and melting curve analysis the iCycler System (BioRad, Hercules, CA, USA) was used.

The reaction mixture consisted of $\mathrm{NH}_{4}$-reaction buffer $\left(16 \mathrm{mM}\left(\mathrm{NH}_{4}\right)_{2} \mathrm{SO}_{4}, 67 \mathrm{mM}\right.$ Tris- $\mathrm{HCl}, 0.01 \%$ (v/v) Tween-20, $\mathrm{pH} 8.8$ at $25^{\circ} \mathrm{C}$, Bioline, Luckenwalde, Germany), $3 \mathrm{mM} \mathrm{MgCl}$ (Bioline, Luckenwalde, Germany), $0.2 \mathrm{mM}$ of each dATP, dTTP, dCTP and dGTP (Bioline, Luckenwalde, Germany), $0.3 \mu \mathrm{M}$ of each primer, $0.25 \mathrm{u}$ BIOTaq DNA polymerase (Bioline, Luckenwalde, Germany), $10 \mathrm{nM}$ fluorescein (BioRad, Hercules, CA, USA), 100,000 times diluted SYBR Green I solution (Invitrogen, Karlsruhe, Germany), $2 \mu \mathrm{l}$ of template DNA and $\mathrm{ddH}_{2} \mathrm{O}$ up to $25 \mu \mathrm{l}$. The quantification of PCR products was performed using filters with optimal settings for SYBR Green I which are $490 \pm 10 \mathrm{~nm}$ for excitation and $530 \pm 15 \mathrm{~nm}$ for emission.

PCR amplification was carried out using an initial denaturation step for $2 \mathrm{~min}$ at $94^{\circ} \mathrm{C}$, which is followed by 36 reaction cycles consisting of a $20 \mathrm{~s}$ denaturation step at $94^{\circ} \mathrm{C}$, an annealing step for $30 \mathrm{~s}$ at $59^{\circ} \mathrm{C}$ and $40 \mathrm{~s}$ at $72^{\circ} \mathrm{C}$. The final elongation was performed for $5 \mathrm{~min}$ at $72^{\circ} \mathrm{C}$. During the amplification process, the detection of fluorescence was carried out in the annealing step of each cycle. To verify amplification of the specific target DNA, a melting curve analysis was included. Melting curves were acquired by heating the samples to $95^{\circ} \mathrm{C}$ for $1 \mathrm{~min}$, cooling to $55^{\circ} \mathrm{C}$ for another min and then slowly increasing the temperature from 65 to $95^{\circ} \mathrm{C}$ at the rate of $0.5^{\circ} \mathrm{C} \mathrm{s}^{-1}$, with a continuous measurement of the fluorescence. The amount of DNA of $V$. longisporum and $V$. dahliae, respectively, was estimated from a calibration curve using increasing amounts of genomic $V$. longisporum DNA from 0.5 to $64.0 \mathrm{pg}$. Preliminary studies confirmed that the amplification is not hampered by the plant matrix. The concentration of $V$. longisporum DNA used for the construction of the calibration curve was estimated by densitometry of agarose gels stained with ethidium bromide, using Lambda Phage DNA as a standard. 


\section{Results}

Disease development

Fourteen dpi, first disease symptoms appeared on $V$. longisporum infected plants, in the form of chlorosis and dark-coloured veins especially on older leaves (Table 2). At $21 \mathrm{dpi}$, all plants inoculated with $V$. longisporum showed stunted growth and moderate to less severe disease symptoms. Thus, $20 \%$ of the plants had symptoms on $50 \%$ or more of the leaves. This corresponds to disease scores from 4 to 8 (see Table 1). In the following weeks the disease developed until 35 dpi when nearly $50 \%$ of the inoculated plants showed severe disease symptoms. Plants inoculated with $V$. dahliae did not express any symptoms significantly different from the control and occasionally, they even looked healthier than the control plants. The corresponding AUDPC values were 46.6 for the control, 45.9 for $V$. dahliae and 71.1 for plants inoculated with $V$. longisporum.

\section{GFP expression in $V$. longisporum and $V$. dahliae}

Overall, 33 transgenic V. longisporum and $20 \mathrm{~V}$. dahliae isolates were obtained. Eighty percent of the hygromycin B-resistant $V$. dahliae and $60 \%$ of the obtained V. longisporum isolates expressed the GFP, which was a success rate similar to reports either on Agrobacterium-mediated transformation (Lagopodi et al. 2001; Oren et al. 2003) or electroporation (Robinson and Sharon 1999). GFP expression was generally high and uniform in conidia and hyphae with the exception of vacuoles that did not show any fluorescence and appeared as dark areas in the fungal cytoplasm (Fig. 2A-D). In contrast to this, microsclerotia did not fluoresce at all, probably because of the melanin deposited in the cell walls. GFP expression remained stable after successive transfers on Czapek Dox medium with and without hygromycin B.

Suitability of GFP-tagged strains vs. classical staining methods

In this study, we compared the suitability of tagging fungi with GFP with conventional fluorescence staining for plant-fungus interaction studies. Due to the fact that GFP is constitutively expressed in the cytoplasm of the transformed fungi, only younger hyphae showed bright fluorescence and are thus well visible under the fluorescence microscope. This hampers a comprehensive analysis of all stages of colonization and infection at one particular time point. In order to localize the fungal structures in the plant tissue we used the overlay feature of the CLSM in order to generate compound images of normal transmission underneath the corresponding fluorescence image. The result, however, was not satisfactory and allowed only for a rough localization of the fungus in the plant tissue (Fig. 2E, F).

By applying acid fuchsin or acridine orange as conventional dyes we obtained a strong staining of all fungal structures but also a faint but distinct staining of cell walls and the plasma membranes allowing for accurate studies of the pathogen invading the plant tissue. As a further problem with the GFP samples, photobleaching occurred after repeated and extended scanning on the same sample sites. In general, this problem can be overcome by reducing the energy level of the laser. However, this option is limited by the fluorescence intensity of the referring object. Regarding all these facts, we concluded that the conventional staining techniques combined with

Table 2 Means of disease scores on B. napus plants inoculated with V. longisporum (+VL) or V. dahliae (+VD) compared to control plants treated with water

\begin{tabular}{llllll}
\hline Treatment & \multicolumn{2}{l}{ Days post-inoculation (dpi) } & 21 & 28 & 35 \\
\cline { 2 - 6 } & 7 & 14 & $2.00( \pm 0.00) \mathrm{a}$ & $2.40( \pm 0.15) \mathrm{a}$ & $2.50( \pm 0.17) \mathrm{a}$ \\
\hline Control & $1.00( \pm 0.00) \mathrm{a}$ & $1.00( \pm 0.00) \mathrm{a}$ & $2.00( \pm 0.00) \mathrm{a}$ & $2.31( \pm 0.15) \mathrm{a}$ & $2.50( \pm 0.16) \mathrm{a}$ \\
$+\mathrm{VD}$ & $1.00( \pm 0.00) \mathrm{a}$ & $1.00( \pm 0.00) \mathrm{a}$ & $3.31( \pm 0.00) \mathrm{a}$ & $3.35( \pm 0.31) \mathrm{b}$ & $4.58( \pm 0.79) \mathrm{b}$ \\
$+\mathrm{VL}$ & $1.00( \pm 0.00) \mathrm{a}$ & $1.42( \pm 0,00) \mathrm{a}$ &
\end{tabular}

Standard error is shown in brackets. Values followed by the same letter do not differ on a significance level of $P \leq 0.05$ (LSD). For disease assessment key see Table 1 
Fig. 2 Confocal microscopy image of Verticillium longisporum and $V$. dahliae expressing GFP. (A) Germinating spore of $V$. longisporum. (B) Hyphae of $V$. dahliae, vacuoles of fungal cells are visible as dark areas in the fluorescing cytoplasm. (C) Mycelium of

V. longisporum showing hyphal dimorphism with very thin and normal, vacuolated hyphae. Arrow heads mark areas of weak fluorescence. (D) Hyphae of V. longisporum. Arrows point to a very weak glowing hypha. $\mathrm{sp}=$ conidium, $\mathrm{v}=$ vacuole. "(E) Fluorescence image of GFP-tagged mycelium of $V$. longisporum on a root of B. napus (48 hpi). (F) Compound micrograph of bright field transmission and corresponding fluorescence images (same view as E )
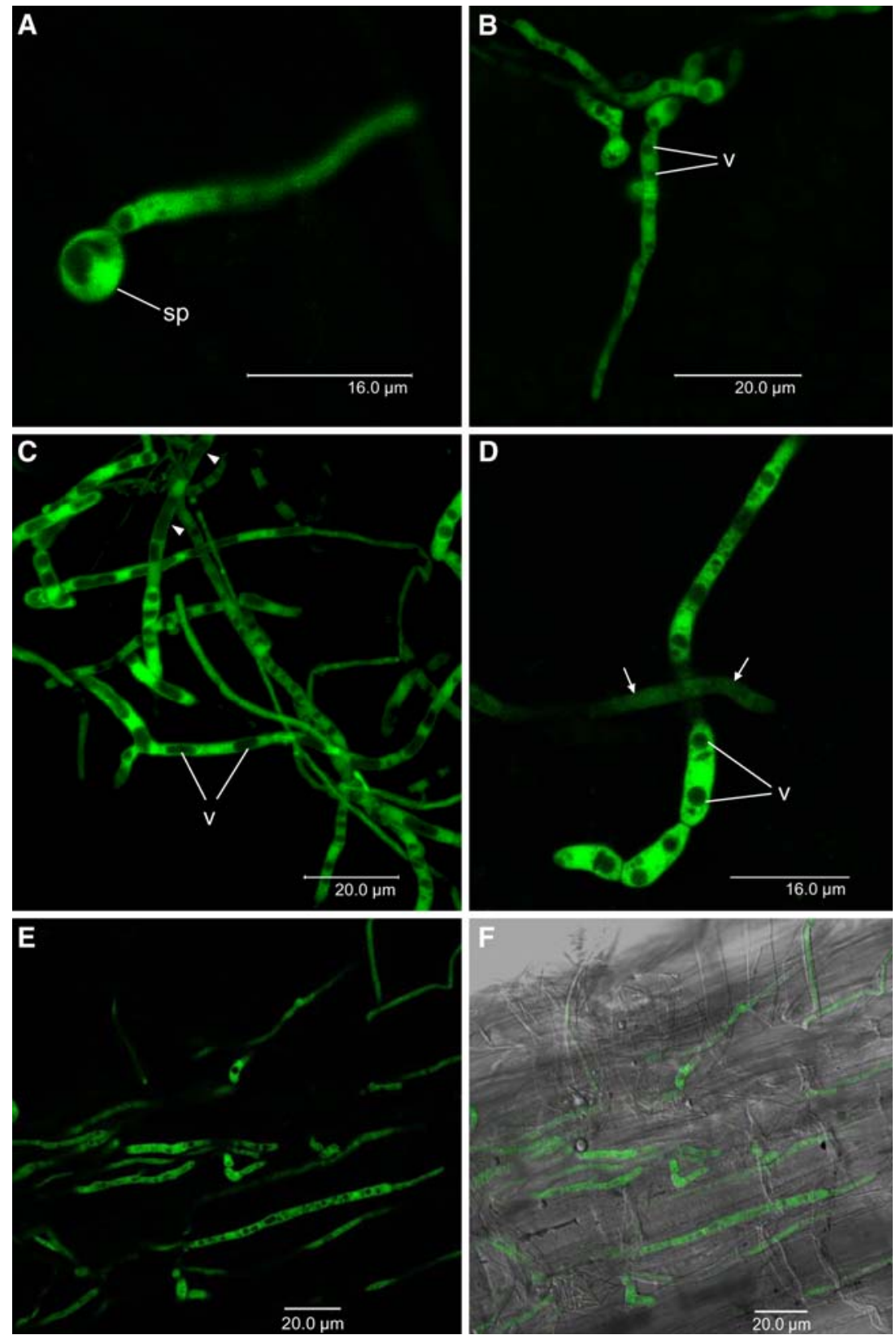

CLSM were superior to the GFP tagging for in situ studies of pathogens at least in the present pathosystems and we therefore decided to continue further studies with fuchsin and acridinorange.

Plant-pathogen interaction studies

Spores of $V$. longisporum and $V$. dahliae started to germinate after in vitro infection 11 hpi. Usually, a secondary germ tube developed in opposite position to the emergence site of the primary germ tube. In the sand culture system, hyphae of both $V$. longisporum and $V$. dahliae were found 24 hpi intensely interwoven with the root hairs close to the main and lateral roots. A tight attachment of hyphae to the root hairs was observed at random positions along the root hair zone for both fungi (Fig. 3A-C). The root tip was the only part of the root, which was not colonised. At 
Fig. 3 Early stages of root colonization by

$V$. longisporum and

$V$. dahliae on oilseed rape, as observed by confocal laser scanning microscopy after staining with acid fuchsin. The classical staining method results in a stable and homogenous bright green fluorescence of the entire fungal biomass and a faint background staining of the plant tissue. A-D: 24 hpi; E, F: 48 hpi. (A) Contact of hyphae of V. longisporum with root hairs. (B) Intermingling of hyphae of $V$. dahliae with root hairs. Already at this stage the fungus produces spores. (C) Attachment (arrow heads) of fungal hyphae of $V$. longisporum to root hairs. (D) V. dahliae, production of conidia inbetween root hairs. (E) Hyphae of $V$. longisporum growing along the junctions of the epidermal cells forming a network. (F) $V$. dahliae growing in an undirected manner on the root surface of B. napus. hy = hypha, $\mathrm{ph}=$ phialide, $\mathrm{r}=$ root, $\mathrm{rh}=$ root hair, $\mathrm{sp}=$ conidium
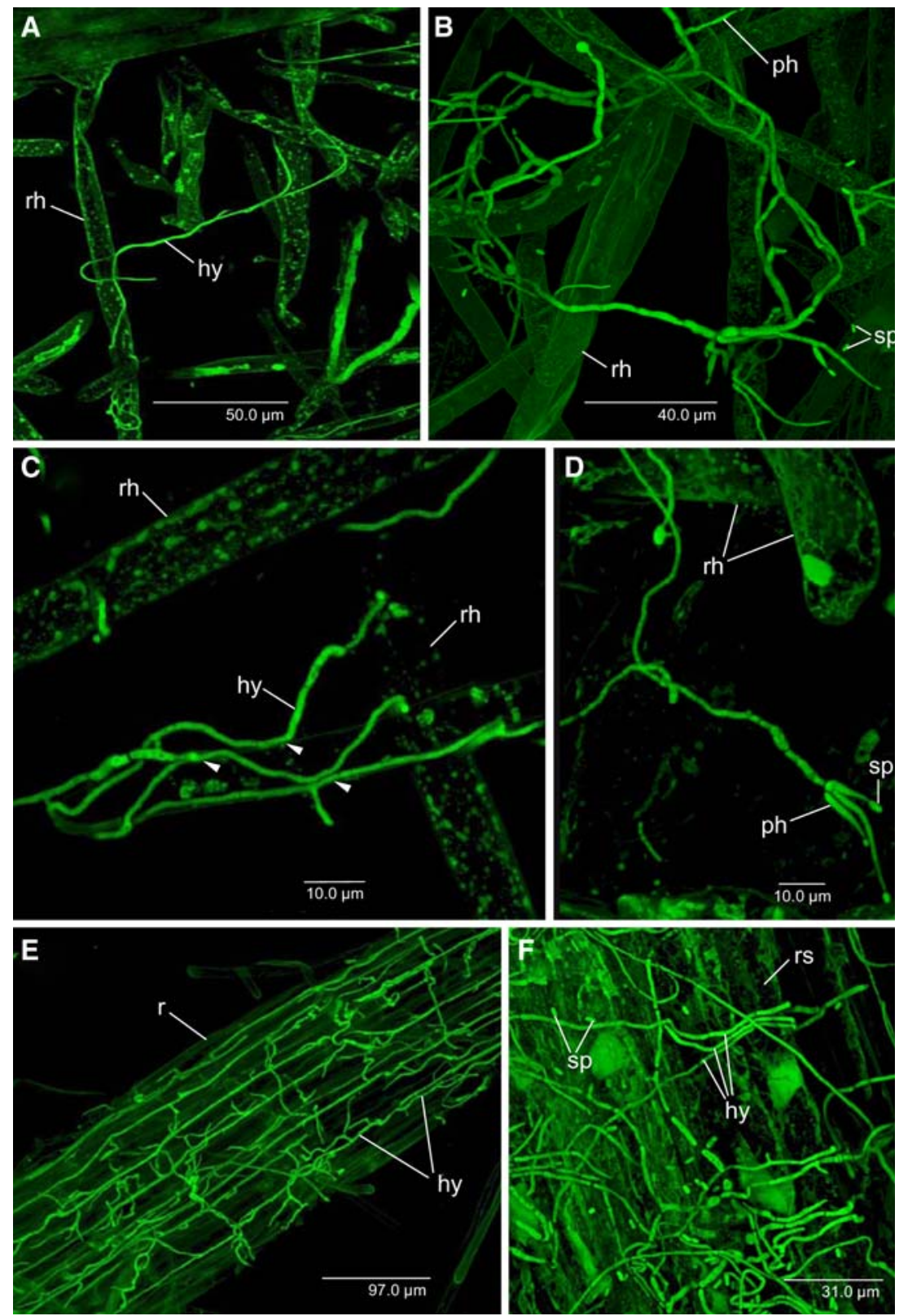

24 hpi, V. dahliae already showed colonization of the root to a much lesser extent than $V$. longisporum and started to produce ample masses of conidia in the vicinity of root hairs (Fig. 3B, D). In contrast, the formation of conidia by $V$. longisporum was never observed outside the roots throughout the investigations.

Hyphae of $V$. longisporum showed growth on and along root hairs towards the root surface. At 36 hpi, the first contacts between hyphae and the root surface were observed. After attachment to the root surface, hyphae of $V$. longisporum grew strictly following the grooves of the junctions of the epidermal cells. At $48 \mathrm{hpi}$, the root surface was covered with a closely attached hyphal net depicting the cellular structure of the root epidermis (Fig. 3E). In contrast, growth of $V$. dahliae hyphae on the root surface was random not following any such pattern (Fig. 3F).

At $60 \mathrm{hpi}$, first penetrations of $V$. longisporum into the roots were observed. The fungus entered the root 
tissue by direct penetration of the epidermal cells without forming any conspicuous infection structures like appressoria or hyphopodia. Only slight hyphal swellings were formed before entering epidermal cells (Fig. 4A), probably due to the accumulation of cytoplasm in the hyphal tip as a response to the mechanical resistance of the plant tissue. Plant cell walls were perforated by a thin penetration peg. In the lumen of the epidermal cells, the hyphae regained their regular diameter (Fig. 4B). Subsequently, hyphae grew intracellularly and intercellularly in the root cortex, in a more or less directed manner towards the central cylinder (Fig. 4C). Whenever growing through cell walls, hyphae showed the typical sequence of swelling, constriction to a narrow infection peg and regaining the regular size after penetration (Fig. 4D). Remarkably, the roots, although intensely colonised by $V$. longisporum, did not show any responses such as discolouration or necrotic lesions. Even host cells invaded by intracellular hyphae showed an intact structure of the cytoplasm.

Verticillium dahliae was also able to penetrate the root tissue, but this occurred much less frequently (Fig. 4E). In the root cortex, $V$. dahliae was preferentially found in the intercellular rather than the intracellular space (Fig. 4F). Also, in the in vitro inoculation system $V$. dahliae started to produce microsclerotia after 2 weeks. Interestingly, microsclerotia of $V$. dahliae were not formed in the roots or on the root surface but were scattered on the surrounding medium. In contrast, microsclerotia of $V$. longisporum were consistently formed in the root cells, which were filled with microsclerotia 3 weeks after inoculation.

Colonisation of the xylem vessels of the shoot with $V$. longisporum started three weeks after inoculation. However, the fungus never managed to colonise the entire vascular system. Moreover, it was restricted to individual vessels which, however, were entirely filled up with mycelium (Fig. 5A, B). Adjacent xylem vessels were easily invaded through plasmodesmata (Fig. 5A). Conidia were formed either by budding (Fig. 5C, D) or on phialides arranged in a typical verticillate manner (not shown).

Real time-PCR analysis

Seven days post-inoculation both $V$. longisporum and $V$. dahliae were detectable in the hypocotyls of infected plants (Table 3). The amount of V. longisporum DNA was substantially higher than that of $V$. dahliae, corroborating the histological studies. The amount of $V$. longisporum continued to increase in the hypocotyl until $35 \mathrm{dpi}$, whereas $V$. dahliae remained at a very low level. In leaves, $V$. longisporum was first detectable in one single plant at $14 \mathrm{dpi}$, then slightly increased until $28 \mathrm{dpi}$, and sharply spread at 35 dpi. In contrast, no significant colonisation of $B$. napus leaves with $V$. dahliae was detected throughout the time of observation.

\section{Discussion}

This study reports on the A. tumefaciens-mediated transformation of the phytopathogenic fungi $V$. longisporum and $V$. dahliae, resulting in the stable expression of GFP. This transformation method proved to be an effective tool to introduce foreign genes into the genome of Verticillium species, as indicated by the relatively high number of gained transformants. In comparison, attempts of a DNAmediated transformation of $V$. dahliae spheroplasts resulted in a low transformation efficiency (Dobinson 1994). The transformants obtained in this study were indistinguishable from the wild-type strain concerning colony morphology, growth rate and pathogenicity/aggressiveness (data not shown). However, the transformants showed differences in the fluorescence intensity due to different levels of GFP expression. This may be caused by positional effects resulting from different sites of integration into the fungal genome. The phenomenon of older hyphae showing a reduced or no expression of GFP has been described earlier in studies on Leptosphaeria spp. and Oculimacula spp. (Eckert et al. 2005). This may be due to the fact that the cytoplasm in senescing mycelium is translocated from the older into younger hyphae.

In our studies we directly compared GFP fluorescence with conventional staining using a fluorescence dye. This analysis clearly revealed a superior performance of the applied fluorochromes as the entire mycelium was made visible regardless of its physiologic state. In addition, the faint non-specific staining of the plant tissue enabled a proper localization of the fungus in the host. Nevertheless, there are still several advantages in the GFP labelling of plant pathogens. First, GFP fluorescence requires no 
Fig. 4 Advanced stages of the interaction of

$V$. longisporum and

$V$. dahliae with roots of

B. napus. Confocal laser scanning microscopy analysis after staining with acid fuchsin and acridine orange (C.). A-C, E, $\mathrm{F}=60$ hpi; $\mathrm{D}=96$ hpi. (A) Hyphae of $V$. longisporum growing along a root hair towards the root surface, penetrating an epidermal cell and growing further into the root cortex.

Asterisks mark the points of intracellular penetration through plant cell walls. (B) Intracellular growth of $V$. longisporum in the root cortex. Arrow heads mark the plant cell wall which is penetrated twice (asterisks). After penetration, hyphae regain their regular diameter. (C) Directed growth of $V$. longisporum in the root cortex towards the xylem. Arrow heads assign points of penetration. (D) Magnified view of the penetration of a plant cell wall (arrow heads) by $V$. longisporum in the root cortex. Asterisk marks the swelling of the hypha before penetrating with a thin penetration peg. (E) Growth of $V$. dahliae in the root cortex of B. napus. Asterisk marks a primary penetration event. (F) Mainly intercellular growth of $V$. dahliae in the root cortex. cw = cell wall, hy = hypha, rh = root hair, $\mathrm{xy}=$ xylem, $\mathrm{xyp}=$ xylem parenchyma
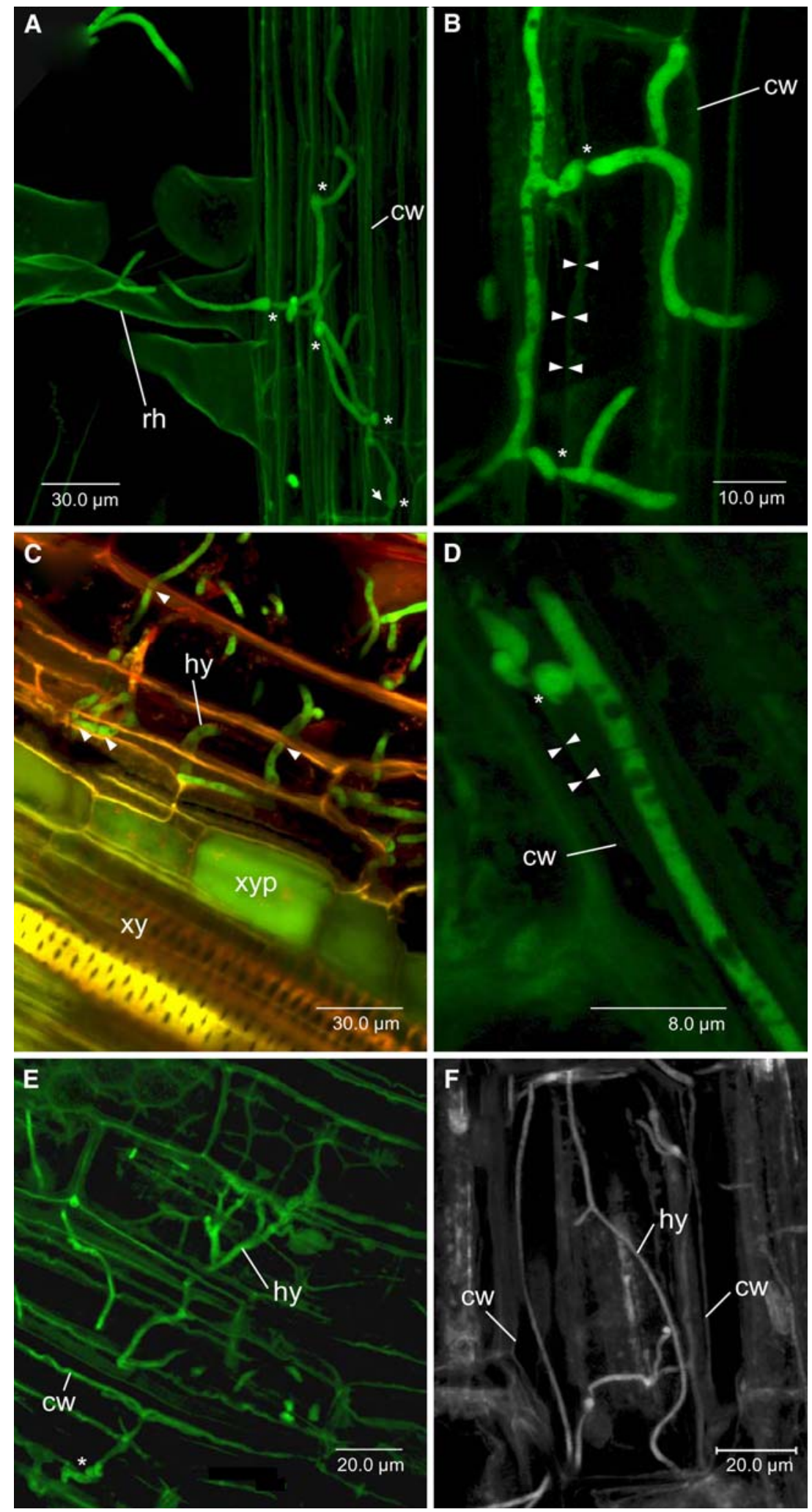
Fig. 5 Colonization of the xylem of B. napus by $V$. longisporum. Confocal laser scanning microscopy analysis after staining with acid fuchsin (21 dpi). (A) Hyphae of $V$. longisporum in xylem vessels of B. napus. Proliferation of mycelium into adjacent vessels through

plasmodesmata (asterisk).

(B) Colonization of a single vessel element filled with mycelium. (C) Hyphal growth and production of conidia in a xylem element. (D) Conidia clumped together at the end of a tracheid. hy = hypha, $\mathrm{xy}=$ xylem elements, $\mathrm{sp}=$ conidia
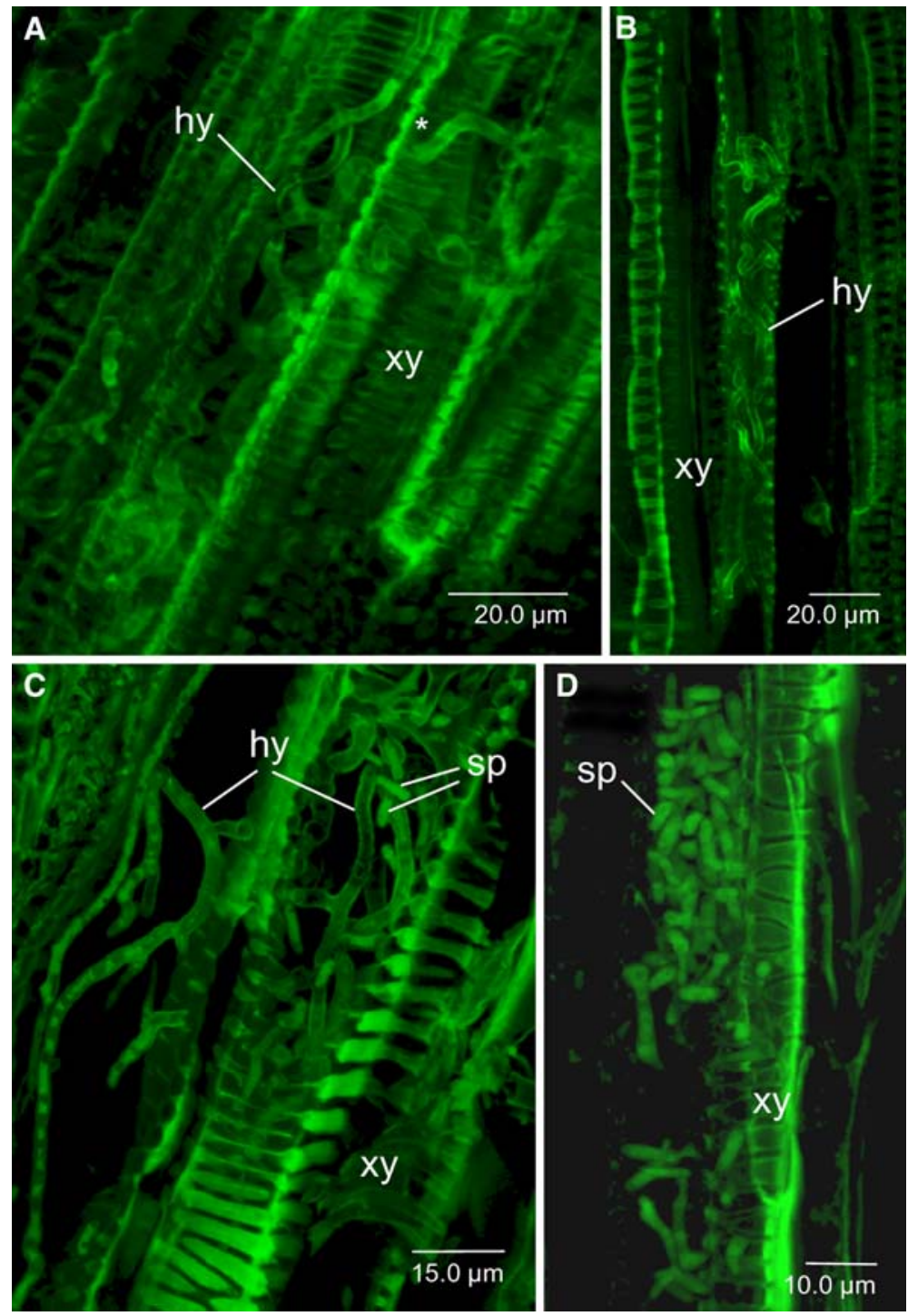

Table 3 Detection of Verticillium-DNA with real-time PCR in tissue samples of B. napus seedlings inoculated with V. longisporum (VL) or V. dahliae (VD)

\begin{tabular}{llllll}
\hline Tissue & \multicolumn{2}{l}{ Leaves } & & \multicolumn{1}{l}{ Hypocotyl } \\
\cline { 2 - 3 } dpi & $n g V L-D N A / g F W$ & $n g V D-D N A / g F W$ & & $n g V L-D N A / g F W$ & $n g V D-D N A / g F W$ \\
\hline 7 & $0.00( \pm 0.00)$ & $0.00( \pm 0.00)$ & $0.00( \pm 0.00)$ & $2.88( \pm 0.89)$ & $0.53( \pm 0.18)$ \\
14 & $0.01( \pm 0.01)$ & $0.02( \pm 0.02)$ & $9.94( \pm 2.79)$ & $0.18( \pm 0.09)$ \\
21 & $0.51( \pm 0.29)$ & $0.01( \pm 0.01)$ & $3.95( \pm 1.65)$ & $0.05( \pm 0.02)$ \\
28 & $0.59( \pm 0.26)$ & $0.06( \pm 0.06)$ & $10.41( \pm 1.52)$ & $2.62( \pm 1.18)$ \\
35 & $6.89( \pm 5.37)$ & $25.58( \pm 6.79)$ & $0.24( \pm 0.12)$ \\
\hline
\end{tabular}

Values are means of the amount of fungal DNA in leaves and hypocotyls; \pm standard error 
co-factors or substrates and allows for a fast processing of the plant material. Further, the risk of potential artefacts is negligible due to the absence of additional chemicals. This enables time-lapse observations in vivo (Lagopodi et al. 2001). Also, studies of pathogens in non-sterile conditions would make GFP tagging the preferential approach.

There are several similarities from our microscopic studies of $V$. longisporum on and in B. napus roots with earlier reports on the infection process of $V$. dahliae on a wide range of host plants (Schnathorst 1981; Beckmann 1987; Gold et al. 1996). However, our studies also provide significant novel information about colonization and infection. This particularly applies to the early interaction, including recognition and first contacts between host and pathogen. We observed that $V$. longisporum initially approaches the roots by following the root hairs. This may be due to a stronger chemical attraction of the fungus to the root hairs than the root surface, as suggested in an earlier study with Fusarium oxysporum f. sp. radicis-lycopersici on tomato roots (Lagopodi et al. 2001). Thereafter, hyphae of $V$. longisporum attached to the root surface where they preferably spread in a typical pattern of superficial hyphae. Primary infection occurs either at the junctions of epidermal root cells or directly into epidermal cells. We never observed penetration at the very root tip or into root hairs. This is in contrast to a former study (Zhou et al. 2006) where infection by $V$. longisporum was primarily localized in lateral roots or root hairs. Further, there was no indication that natural wounds from emerging lateral roots are necessary for infection, which is in agreement with previous studies on GFP-expressing F. oxysporum f. sp. radicis-lycopersici on tomato roots (Lagopodi et al. 2001) and Fusarium verticillioides on maize roots (Oren et al. 2003). It may therefore be speculated whether there exists a common mode of root colonization and infection by vascular pathogens, in which the pathogens are chemically directed to the root hair zone where they first attach and then penetrate directly into the epidermal cells (Oren et al. 2003).

The observation that even massive inoculation with $V$. longisporum results in a colonisation merely restricted to individual xylem vessels, while others remain entirely free of the fungus, has not so far been reported. Nonetheless, $V$. longisporum was able to penetrate into adjacent vessels after being trapped at vessel end walls, which was similar to recent studies of $V$. longisporum (Zhou et al. 2006) and V. albo-atrum (Heinz et al. 1998), but has not been shown so far for $V$. dahliae. This partial colonisation may be an explanation for the absence of wilting symptoms in $V$. longisporum-infected oilseed rape, as observed both in the greenhouse and in the field. However, wilting is not only caused by the physical blocking of vessels but may also be induced by wilting toxins, which, however, are yet unknown for V. longisporum.

The interaction of $V$. dahliae with $B$. napus roots completely differs that of from $V$. longisporum. The undirected growth of hyphae which are only loosely attached to the root surface and the early, massive production of conidia and microsclerotia outside the root tissue strongly suggest that $B$. napus is not a suitable host plant for $V$. dahliae. This colonization pattern might be the result of stress or a deficiency situation derived from a non-host interaction. Nevertheless, $V$. dahliae was infrequently able to penetrate and colonize the root tissue, however, it rarely reached the shoots or leaves as indicated by histological and real-time PCR analyses. In conclusion, the present results demonstrate that the poor susceptibility of B. napus to $V$. dahliae is only partly due to the restriction of penetration but mainly related to inhibition of systemic growth into the shoot, which is in agreement with earlier observations (Zhou et al. 2006). While V. longisporum, upon penetration, readily spreads into the vascular system, the systemic growth of $V$. dahliae is strongly inhibited due to yet unknown factors. This kind of restricted invasion of a vascular pathogen represents an interesting intermediate case of parasitism, as root penetration is not followed by invasive spread in the host. As disease symptoms are lacking, the lifestyle of $V$. dahliae after infection resembles an endophytic state and implies a systemic non-host resistance. Similarly, a restriction to the basal plant parts has been found with certain other wilt pathogens in plants with enhanced host plant resistance (Beckman 1987).

The mechanisms governing the expression of this specific type of non-host resistance are not known. Increased synthesis of the aromatic glucosinolate gluconasturtiin in the roots appeared to be a major factor in the active resistance response of oilseed rape against a non-pathogenic $V$. dahliae strain which 
failed to colonize the plant (Karapapa et al. 1997a). The pathogenic $V$. longisporum strain was either capable of suppressing gluconasturtiin synthesis in roots, or failed to trigger its synthesis by avoiding recognition. This implies an adaptation of $V$. longisporum to oilseed rape as its host, potentially by being less sensitive to this kind of host-specific defence, as compared to $V$. dahliae. This is corroborated by studies in which the pathogenicity of $V$. longisporum on high and low glucosinolateproducing genotypes of $B$. napus did not differ (Heale and Karapapa 1999). Similarly, Zhou et al. (2006) did not find any differences in the growth of $V$. longisporum on agar containing plant extracts from high or low glucosinolate oilseed rape varieties.

Finally, the present study provides cytological evidence that infrequent infection of OSR with $V$. dahliae may occur, but vascular colonization and disease development can be excluded. This finding confirms earlier studies on host range (Zeise and von Tiedemann 2002b) and is of importance in fields where oilseed rape is grown in rotation with susceptible hosts of $V$. dahliae such as potato, strawberry or sugar beet (Pegg and Brady 2002), and where enhanced soil infestation with microsclerotia from both Verticillium species may occur.

Acknowledgements $\mathrm{We}$ are grateful to the breeding companies represented by the GFP (Gemeinschaft zur Förderung der privaten deutschen Pflanzenzüchtung e.V.) for constant support and fruitful cooperation. The funding of this study by GFP and FNR (German Ministry of Food, Agriculture and Consumer Protection) is acknowledged.

\section{References}

Babadoost, M., Chen, W., Bratsch, A. D., \& Eastman, C. E. (2004). Verticillium longisporum and Fusarium solani: two new species in the complex of internal discolouration of horseradish roots. Plant Pathology, 53, 669-676.

Beckmann, C. H. (1987). The nature of wilt diseases of plants. St. Paul, MN, USA: APS Press.

Bevan, M. (1984). Binary Agrobacterium vectors for plant transformation. Nucleic Acids Research, 12, 8711-8721.

Bhat, R. G., \& Subbarao, K. V. (1999). Host range specificity in Verticillium dahliae. Phytopathology, 89, 1218-1225.

Bolwerk, A., Lagopodi, A., Lugtenberg, B. J. J., \& Bloemberg, G. V. (2005). Visualization of interactions between a pathogenic and a benefical Fusarium strain during biocontrol of tomato foot and root rot. Molecular Plant-Microbe Interactions, 18, 710-721.

Buckley, P. M., Wyllie, T. D., \& DeVay, J. E. (1969). Fine structure of conidia and conidium formation in Verticil- lium albo-atrum and V. nigrescens. Mycologia, 61, 240250.

Bundock, P., den Dulk-Ras, A., Beijersbergen, A., \& Hoykaas, P. J. J. (1995). Trans-kingdom T-DNA transfer from Agrobacterium tumefaciens to Saccharomyces cerevisiae. European Molecular Biology Organization, 14, 32063214.

Campbell, C. L., \& Madden, L. V. (1990). Introduction to plant disease epidemiology. New York, USA: John Wiley.

Chalfie, M., \& Kain, S. (1998). Green fluorescent protein. properties, applications and protocols. New York: WileyLiss, Inc.

Collins, A., Okoli, C. A. N., Morton, A., Parry, D., Edwards, S. G., \& Barbara, D. J. (2003). Isolates of Verticillium dahliae pathogenic to crucifers are of at least three distinct molecular types. Phytopathology, 93, 364-376.

Covert, S. F., Kapoor, P., Lee, M., Briley, A., \& Nairn, C. J. (2001). Agrobacterium tumefaciens-mediated transformation of Fusarium circinatum. Mycological Research, 105, 259-264.

Daebeler, F., Amelung, D., \& Zeise, K. (1988). VerticilliumWelke an Winterraps-Auftreten und Bedeutung. Nachrichtenblatt Pflanzenschutzdienst DDR, 42, 71-73.

Dimond, A. E. (1970). Biophysics and biochemistry of the vascular wilt syndrome. Annual Review of Phytopathology, 8, 301-322.

Dixelius, C., Happstadius, I., \& Berg, G. (2005). Verticillium wilt on Brassica oil crops-a Swedish perspective. Journal of the Swedish Seed Association, 115, 36-48.

Dixon, G. R., \& Pegg, G. F. (1972). Changes in the amino acid content of tomato xylem sap following infection with strains of Verticillium albo-atrum. Annals of Botany, 36, 147-154.

Dobinson, K. F. (1994). Genetic transformation of the vascular wilt fungus Verticillium dahliae. Canadian Journal of Botany, 73, 710-715.

Domsch, K. H., Gams, W., \& Anderson, T. -H. (1980). Nectria (Fr) 1849, Verticillium Nees ex Link 1824. In: Compendium of Soil Fungi (pp. 829-845), Vol 1. New York: Academic Press.

Eckert, M., Maguire, K., Urban, M., Foster, S., Fitt, B., Lucas, J., \& Hammond-Kosack, K. (2005). Agrobacterium tumefaciensmediated transformation of Leptosphaeria spp. and Oculimacula spp. with the reef coral gene DsRed and the jellyfish gene gfp. FEMS Microbiology Letters, 253, 67-74.

Fahleson, J., Lagercrantz, U., Hu, Q., Steventon, L. A., \& Dixelius, C. (2003). Estimation of genetic variation among Verticillium isolates using AFLP analysis. European Journal of Plant Pathology, 109, 361-371.

Gold, J., Lee, B., \& Robb, J. (1996). Colonization of tomatoes by Verticillium dahliae: determinative phase II. Canadian Journal of Botany, 74, 1279-1288.

Green, R. J. J. (1981). An overview. In M. E. Mace, A. A. Bell, \& C. H. Beckman (Eds.), Fungal wilt diseases of plants (pp. 1-24). New York: Academic Press.

Günzelmann, H., \& Paul, V. H. (1990). Zum Auftreten und zur Bedeutung der Verticillium-Welke an Raps in der Bundesrepublik Deutschland in 1989. Raps, 8, 23-25.

Hanahan, J. (1983). Studies on transformation of Escherichia coli with plasmids. Journal of Molecular Biology, 166, 557-580. 
Happstadius, I., Ljunberg, A., Kristiansson, B., \& Dixelius, C. (2003). Identification of Brassica oleracea germplasm with improved resistance to Verticillium wilt. Plant Breeding, 122, 30-34.

Heale, J. B., \& Karapapa, V. K. (1999). The Verticillium threat to Canada's major oilseed crop: Canola. Canadian Journal of Plant Pathology, 21, 1-7.

Heinz, R., Lee, S. W., Saparno, A., Nazar, R. N., \& Robb, J. (1998). Cyclical systemic colonization in Verticilliuminfected tomato. Physiological and Molecular Plant Pathology, 52, 385-396.

Hood, E. E., Helmer, G. L., Fraley, R. T., \& Chilton, M. D. (1986). The hypervirulence of Agrobacterium tumefaciens A281 is encoded in a region of pTiBo542 outside of TDNA. Journal of Bacteriology, 168, 1291-1301.

Horowitz, S., Freeman, S., \& Sharon, A. (2002). Use of green fluorescent protein-transgenic strains to study pathogenic and nonpathogenic lifestyles in Colletotrichum acutatum. Phytopathology, 92, 743-749.

Johannson, A., Goud, J. -K., \& Dixelius, C. (2006). Plant host range of Verticillium longisporum and microsclerotia density in Swedish soils. European Journal of Plant Pathology, 114, 139-149.

Karapapa, V. K., Baig, M. A., Heale, J. B., \& Rossiter, J. T. (1997a). Glucosinolate response in winter oilseed rape Brassica napus ssp. oleifera to Verticillium dahliae (nonpathogenic), V. longisporum comb. Nov., (Karapapa, Bainbridge and Heale, 1997) (pathogenic). In E. C. Tjamos, R. C. Rowe, J. B. Heale, \& D. R. Fravel (Eds.), Advances in Verticillium research and disease management. St. Paul, Minnesota: APS Press.

Karapapa, V. K., Bainbridge, B. W., \& Heale, J. B. (1997b). Morphological and molecular characterisation of Verticillium longisporum comb. nov., pathogenic to oilseed rape. Mycological Research, 101, 1281-1294.

Komari, T., Halperin, W., \& Nester, E. W. (1986). Physical and functional map of supervirulent Agrobacterium tumefaciens tumor-inducing plasmid pTiBo542. Journal of Bacteriology, 166, 88-94.

Krüger, W. (1989). Untersuchungen zur Verbreitung von Verticillium dahliae Kleb. und anderen Krankheits- und Schaderregern bei Raps in der Bundesrepublik Deutschland. Nachrichtenblatt des Deutschen Pflanzenschutzdienstes, 41, 49-56.

Lagopodi, A. L., Ram, A. F. J., Lamers, G. E. M., \& Punt, P. J. (2001). Novel aspects of tomato root colonization and infection by Fusarium oxysporum f. sp. radicis-lycopersici revealed by confocal laser scanning microscopic analysis using the green fluorescent protein as a marker. Molecular Plant-Microbe Interactions, 15, 172-179.

Lazo, G. R., Stein, P. A., \& Ludwig, R. A. (1991). A DNA transformation-competent Arabidopsis genomic library in Agrobacterium. Bio/Technology, 9, 963-967.

Lorang, J. M., Tuori, R. P., Martinez, J. P., Sawyer, T. L., Redman, R. S., Rollins, J. A., Wolpert, T. J., Johnson, K. B., Rodriguez, R. J., Dickman, M. B., Ciufetti, L. M. (2001). Green fluorescent protein is lighting up fungal biology. Applied and Environmental Microbiology, 67, 1987-1994.

Maor, R., Puyesky, M., Horwitz, B. A., \& Sharon, A. (1998). Use of green fluorescent protein (GFP) for studying development and fungal-plant interaction in Cochliobolus heterostrophus. Mycological Research, 102, 491-496.

Maniatis, T., Fritsch, E. F., \&Sambrook, J. (1982). In Molecular cloning: A laboratory manual. Cold Spring Harbor: Cold Spring Harbor Laboratory.

Melouk, H. (1992). Verticillium. In L. L. Singleton, J. D. Mihail, \& C. M. Rush (Eds.), Methods for research on soilborne pathogenic fungi (pp. 175-178). St Paul, MN, USA: APS Press.

Mol, L., \& Scholte, K. (1995). Formation of microsclerotia of Verticillium dahliae Kleb. on various plant parts of two potato cultivars. Potato Research, 38, 143-150.

Neumann, M. J., \& Dobinson, K. F. (2003). Sequence tag analysis of gene expression during pathogenic growth and microsclerotia development in the vascular wilt pathogen Verticillium dahliae. Fungal Genetics and Biology, 38, 54-62.

Oren, L., Ezrati, S., Cohen, D., \& Sharon, A. (2003). Early events in the Fusarium verticillioides-maize interaction characterized by using a green fluorescent proteinexpressing transgenic isolate. Applied and Environmental Microbiology, 69, 1695-1701.

Pegg, G. F. (1981). Biochemistry and physiology of pathogenesis. In M. E. Mace, A. A. Bell, \& C. H. Beckman (Eds.), Fungal wilt diseases of plants (pp. 193-253). New York: Academic Press.

Pegg, G. F. (1984). The impact of Verticillium diseases in agriculture. Phytopathologia Mediterranea, 23, 176-192.

Pegg, G. F. (1985). Life in a black hole-the micro-environment of the vascular pathogen. Transactions of the British Mycological Society, 85, 1-20.

Pegg G. F., \& Brady B. L. (Eds.) (2002). Hosts. In: Verticillium Wilts (pp. 193-340). Wallingford, UK: CAB Publishing.

Punt, P. J., Oliver, R., Dingemanse, M. A., Pouwels, P. H., \& van den Hondel, C. A. M. J. J. (1987). Transformation of Aspergillus based on the Hygromycin B resistance marker from Escherichia coli. Gene, 56, 117-124.

Robinson, M., \& Sharon, A. (1999). Transformation of the bioherbicide Colletotrichum gloeosporioides f. sp. aeschynomene by electroporation of germinated conidia. Current Genetics, 36, 98-104.

Rowe, R. R., \& Powelson, M. L. (2002). Potato early dying: management challenges in a changing production environment. Plant Diseases, 86, 1184-1193.

Schnathorst, W. C. (1981). Life cycle and epidemiology of Verticillium. In M. E. Mace, A. A. Bell, \& C. H. Beckmann (Eds.), Fungal wilt diseases of plants (pp. 81-111). New York: Academic Press.

Shan, X. C., \& Goodwin, P. H. (2004). Monitoring host nuclear migration and degradation with green fluorescent protein during compatible and incompatible interactions of Nicotiana tabacum with Colletotrichum species. Journal of Phytopathology, 152, 454-560.

Short, J. M., Fernandez, J. M., Sorge, J. A., \& Huse, W. D. (1988). Lambda ZAP: a bacteriophage lambda expression vector with in vivo excision properties. Nucleic Acid Research, 16, 7583-7600.

Söchting, H. P., \& Verreet, J. -A. (2004). Effects of different cultivation systems (soil management, nitrogen fertilization) on the epidemics of fungal diseases in oilseed rape (Brassica napus L. var. napus). Journal of Plant Diseases and Protection, 111, 1-29. 
Spellig, T., Bottin, A., \& Kahmann, R. (1996). Green fluorescent protein (GFP) as a new vital marker in the phytopathogenic fungus Ustilago maydis. Molecular and General Genetics, 252, 503-509.

Stark, C. (1961). Das Auftreten der Verticillium-Tracheomykosen in Hamburger Gartenbau-Kulturen. Gartenbauwissenschaft, 26, 493-528.

Subbarao, K. V., Chassot, A., Gordon, T. R., Hubbard, J. C., Bonello, P., Mulin, R., Okamoto, D., Davis, R. M., \& Koike, S. T. (1995). Host range of Verticillium dahliae from cauliflower and genetic relationships and cross pathogenicities of isolates from different crops. Phytopathology, 85, 1105-1112.

Svenson, C. H., \& Lerenius, C. (1987). An investigation on the effect of Verticillium wilt (Verticillium dahliae Kleb.) on oilseed rape. Working group integrated control in oilseed rape. IOBC/WPRS Bulletin, X/4, 30-34.

Tsien, R. Y. (1998). The green fluorescent protein. Annual Review of Biochemistry, 67, 509-544.

Van Alfen, N. K. (1989). Molecular bases for virulence and avirulence of fungal wilt pathogens. In E. C. Tjamos \& C. H. Beckman (Eds.), Vascular wilt diseases of plants (pp. 19-32). Berlin: Springer.

Wen-Jun, S., \& Forde, B. G. (1989). Efficient transformation of Agrobacterium spp. by high voltage electroporation. $\mathrm{Nu}$ cleic Acid Research, 17, 8385.

Wood, R. K. S. (1961). Verticillium wilt of tomatoes and the role of pectic and cellulolytic enzymes. Annals of Applied Biology, 49, 120-139.

Xiao, C. L., \& Subbarao, K. V. (2000). Effects of Irrigation and Verticillium dahliae on cauliflower root and shoot growth dynamics. Phytopathology, 90, 995-1004.

Zeise, K., \& Seidel, D. (1990). Zur Entwicklung und Schadwirkung der Verticillium- Welkekrankheit am Winterraps. Raps, 8, 20-22.
Zeise, K. (1992). Gewächshaustest zur Resistenzprüfung von Winterraps (Brassica napus L. var. oleifera Metzger) gegen den Erreger der Rapswelke Verticillium dahliae Kleb. Nachrichtenblatt Deutscher Pflanzenschutzdienst, 44, 125-128.

Zeise, K., \& von Tiedemann, A. (2001). Morphological and physiological differentiation among vegetative compatibility groups of Verticillium dahliae in relation to $V$. longisporum. Journal of Phytopathology, 149, 469-475.

Zeise, K., \& von Tiedemann, A. (2002a). Application of RAPD-PCR for virulence type analysis within Verticillium dahliae and Verticillium longisporum. Journal of Phytopathology, 150, 557-563.

Zeise, K., \& von Tiedemann, A. (2002b). Host specialization among vegetative compatibility groups of Verticillium dahliae in relation to Verticillium longisporum. Journal of Phytopathology, 150, 112-119.

Zhou, L., Hu, Q., Johannson, A., \& Dixelius, C. (2006). Verticillium longisporum and Verticillium dahliae: Infection and disease in Brassica napus. Plant Pathology, 55, 137144.

Zielenski, D., \& Sadowski, C. (1995). A preliminary study on Verticillium dahliae Kleb. in winter oilseed rape in Poland. In D. Murphy (Ed.), Proceedings of the 9th International Rapeseed Conference, Cambridge. 4-7 July 1995. GciRC, Cambridge, UK, 649-651.

Zou, W. J., Yoneyama, K., Takeuchi, Y., Iso, S., Rugmekarat, S., Chae, S. H., Sato, D., \& Joel, D. M. (2004). In vitro infection of host roots by differentiated calli of the parasitic plant Orobranche. Journal of Experimental Botany, 55, 899-907. 